\title{
Inner Ear
}

National Cancer Institute

\section{Source}

National Cancer Institute. Inner Ear. NCI Thesaurus. Code C12499.

The portion of the ear located within the temporal bone that is involved in both hearing and balance and includes the semicircular canals, vestibule, and cochlea. (from American Heritage Dictionary online) 